\title{
EVOLUCIÓN RECIENTE Y TENDENCIAS DE LAS ESTRUCTURAS AGRARIAS EN EL MEDIO VINALOPÓ: EL MERCADO DE LA TIERRA EN EL MUNICIPIO DE MONFORTE DEL CID (1980-1991) ${ }^{1}$
}

\author{
A. M. Rico Amorós \\ J. J. Sellés Pérez
}

\section{RESUMEN}

Este artículo pretende analizar el mercado de la tierra en el Medio Vinalopó (Alicante), su dinamismo, los agentes que lo han protagonizado, y sus consecuencias sobre la evolución reciente de las estructuras agrarias. Para ello, se ha elegido el municipio de Monforte del Cid durante el período 1980-1991. Los siniestros meteorológicos, la carencia de agua para riego, los problemas de comercialización y la falta de rentabilidad económica de las explotaciones agrarias han provocado un destacado descenso de las transmisiones de tierra, mantenidas en gran medida por inversiones destinadas a usos no agrarios.

Palabras clave: mercado de la tierra, explotación familiar, propiedad agraria, adquirentes, cesionarios.

\begin{abstract}
This paper deals an analysis of the recent changes that have taken place in landmarket in the Medio Vinalopó (Alicante), their dynamism, the agents protagonist and the consequences on the recent evolution of the land structures. To this effect the study analyses the town of Monforte del Cid during the 1980-1991 period. Catastrophic atmospheric events, scarce amount of water, marketing's problems, and global scarce economic profitability has caused a very notable demotion of land transfer, wich keeps going because of non agrarian capital investment.
\end{abstract}

Key words: land market, family working, agrarian property, buyers, sellers.

1 El presente artículo constituye la continuación de una investigación realizada en 1988 bajo la dirección del Catedrático de Geografía Humana de la Universidad de Valencia D. Juan Romero González. Los resultados alcanzados entonces, y su comparación con otros modelos locales del mercado de la tierra puede consultarse en:

-ROMERO, J.; VERA, J. F.; OBIOL, E.: El mercado de la tierra en el País Valenciano. Institución Valenciana de Estudios e Investigación, (mecanografiado e inédito), Valencia, 1988. 
Uno de los aspectos a los que se ha de otorgar una mayor atención en un análisis de estructuras agrarias es su evolución reciente, y cómo la misma, conducida con criterios eminentemente territoriales, puede verse afectada por los resultados económicos alcanzados por las explotaciones agrarias. Al igual que otros espacios agrarios de nuevas transformaciones en regadío, las estructuras agrarias de la comarca alicantina del Medio Vinalopó - especializada en la producción de uva de mesa embolsada en formas apoyadas-, no son ajenas a la crisis de rentabilidad económica de sus explotaciones agrarias, hecho éste que ha influido también en un menor dinamismo de los movimientos de compra-venta de la tierra.

Por su representatividad, para evaluar dichas tendencias se ha optado por analizar un modelo local del mercado de la tierra: Monforte del Cid durante el período 1980-1991; objetivo éste que tampoco debe desprenderse de unos condicionantes estructurales imperantes con leves matices de grado, en todo el Medio Vinalopó como son: un sistema de abastecimiento de agua para riego dependiente de recursos alumbrados en acuíferos sobreexplotados; el cambio de signo de los procesos de transformación en regadío y el abandono de numerosas explotaciones, por la citada crisis de rentabilidad económica; la crisis de los canales tradicionales de comercialización; el elevado peso específico que ejerce la agricultura como fuente de ingresos complementarios; un segmento muy reducido de explotaciones agrarias dirigidas por agricultores profesionales, y edades muy avanzadas de los existentes. Por otro lado, no parece tampoco que dichas características vayan a favorecer una evolución progresiva de las estructuras agrarias de la comarca, por encontrarse muy distantes de los objetivos de la Política Agraria Comunitaria que apuestan definitivamente por unas explotaciones familiares prioritarias, de mediano tamaño, dirigidas por agricultores profesionales, capaces de ofrecer resultados económicos suficientes para garantizar su supervivencia y desarrollo.

Hay que señalar que en espacios de regadío intensivo como el que nos ocupa, los vínculos jurídicos — propiedad - y los económicos —explotación — de un agricultor con la tierra suelen poseer un rasgo común: explotaciones y propiedad agraria presentan una estructura de tamaño similar. No parece totalmente acertado atribuir los males que afectan a la agricultura intensiva del Vinalopó a un ajuste estructural claramente divergente del operado en otros países europeos, puesto que los procesos de urbanización e industrialización del eje del Vinalopó han tenido como efecto la multiplicación del número de explotaciones agrarias, y una reducción del tamaño de las mismas. Y ello, por dos razones $^{2}$ :

- debido a los beneficios económicos que ofrecía hasta épocas recientes la uva de mesa, y

- a que esos beneficios estimularon la difusión de la agricultura a tiempo parcial.

Ambos factores han favorecido los procesos de puesta en valor del suelo agrario, y han ayudado a la propagación de la agricultura moderna de regadíos intensivos en parcelas de reducido tamaño.

En el presente trabajo se analiza el mercado de la tierra en Monforte del Cid municipio pionero en las transformaciones de regadío y en la introducción del monocultivo de la uva de mesa embolsada. Para ello se han consultado los partes anuales de altas y bajas de

2 Vid. ROMERO GONZÁLEZ, J.: «La agricultura valenciana en el proceso de industrialización y urbanización. Cambios estructurales en el período 1950-1990». En Medio siglo de cambios agrarios en España, (Eds. Gil Olcina, A. y Morales Gil, A.), Instituto de Cultura Juan Gil-Albert, Alicante, pp. 363-392. 
asociados de la Comunidad de Regantes ${ }^{3}$ y el Padrón de Derramas de la Guardería Rural ${ }^{4}$ (1980-87), el Directorio de Explotaciones agrarias ${ }^{5}$.

\section{El mercado de la tierra en Monforte del Cid (1980-91)}

Los dos procesos que determinan modificaciones de la estructura de la propiedad agraria son la compraventa de tierras y las transmisiones por herencia, sin olvidar que los procesos de urbanización e industrialización interfieren también en el mercado de la tierra al favorecer la participación de agentes no agrarios que invierten en tierras para usos residenciales e industriales.

A lo largo de la década de los ochenta, la expansión de la agricultura de regadío, en una coyuntura económica favorable, se materializó en un gran dinamismo y estimuló subidas espectaculares de los precios de compra de la tierra, alcanzándose en algunas operaciones 5 millones de pts./ha, realidad bien distinta a la actual con precios de compraventa que pocas veces superan la mitad de la cifra mencionada. Incluso, tierras que por ubicación ventajosa se vieron beneficiadas por mecanismos de expropiación para la realización de la Autovía de Levante — que atraviesa el término municipal de Monforte-, o por procesos de promoción de suelo industrial, a través de iniciativas públicas (Polígono del SEPES) y privadas (campo de golf), alcanzaron cotizaciones superiores a los 6.000 .000 pts./Ha.

Un factor decisivo en el declive de este panorama fueron los catastróficos efectos de los episodios atmosféricos de junio de 1988 (sucesión de tormentas de pedrisco) y septiembre de 1989 (lluvias torrenciales). A partir de este momento, y agravada por la difícil situación de los mercados de productos agrarios, las estrategias de compraventa para fines agrarios fueron frenadas por los mismos estímulos que la dinamizaron. En la actualidad las explotaciones que mejor resisten los embates de la crisis son las que generan ingresos principales y, entre ellas, las familiares que comercializan su propia producción; éstas últimas se muestran muy reacias a adquirir nuevos predios que puedan desbordar la capacidad de trabajo de la unidad familiar, por el pesado lastre económico que supone los costes laborales.

Por su parte, las explotaciones agrarias que se ejercen como fuente de ingresos complementarios más dispuestas a vender, no encuentran precios competitivos, a no ser que medien intereses especulativos.

Entre 1980 y 1991 se realizaron 1.324 transacciones de tierras en Monforte del Cid, $70 \%$ de las cuales fueron compraventas y el resto transmisiones hereditarias (vid. fig. $\mathrm{n}^{\mathrm{o}} 1$ ). La superficie transferida en estos cambios de propiedad (16.611 tahúllas $\left.{ }^{6}\right)$ representa el $24 \%$ de la superficie total del municipio; más allá incluso, por la naturaleza de la fuente utilizada - Comunidad de Regantes de Monforte del Cid-, las citadas transmisiones han movilizado un $44 \%$ —unas 4.305 has — de la superficie regable municipal ${ }^{7}$.

3 Esta fuente resulta de total fiabilidad. En los partes se anota la identidad de las partes implicadas en la transacción, la superficie y la ubicación de la parcela objeto de transmisión. Estas fichas determinan los derechos — dotaciones de agua - y caras — derramas — de las parcelas cedidas.

4 Este documento tiene carácter recaudatorio con el fin de sufragar los gastos de las Patrullas rurales. En él consta nombre, domicilio de residencia, y superficie poseída.

5 En él se ofrecen datos relativos a la dedicación profesional del titular, edad, domicilio, $\mathrm{n}^{\mathrm{o}}$ de empleados, maquinaria poseída, superficie total de la explotación, y naturaleza del aprovechamiento agrario (cultivos).

6 Una tahúlla equivale a $1.185 \mathrm{~m}^{2}$.

7 Hay que señalar que la propiedad de algunas parcelas ha sido transmitida en más de una ocasión, éste hecho, aunque poco habitual, no es inusitado, en particular en parcelas transmitidas por herencia a descendientes no agrarios que al no ejercer la explotación de la tierra la vendieron, aprovechando la coyuntura favorable del mercado durante el período 1983-87. 
Las tendencias del mercado de la tierra atravesaron 3 etapas claramente diferenciadas, por número de transacciones y tahúllas movilizadas:

$1^{\text {a }}$. 1980-1981. En esta etapa sólo cambian de manos 685 tahúllas (124 transacciones). Es una etapa de escaso dinamismo, debido a la crisis de suministros de agua para riego, al agotarse, por la cruenta sequía, los pozos de agua para regadío de los acuíferos de la Sierra del Cid que suministraban al municipio.

$2^{\mathrm{a}}$. 1982-86. La llegada de aguas para riego desde pozos perforados por el IRYDA en Biar abre una etapa de gran dinamismo, con más de 1.000 tahúllas anuales transferidas. Un dato relevante de la elevada rentabilidad alcanzada, en estos años, en las explotaciones dedicadas al cultivo de uva de mesa, son los precios que llegaron a pagarse en las subastas del agua para riego $\left(55 \mathrm{pts} . / \mathrm{m}^{3}\right)^{8}$.

$3^{\mathrm{a}}$. 1987-91. El dinamismo de las transacciones se mantiene en este trienio a pesar del desarrollo de una serie de factores desfavorables (descenso de exportaciones por competencia de Italia; malas cosechas por siniestros meteorológicos —riadas de octubre y noviembre de 1987, granizos de junio de 1988 y lluvias torrenciales de septiembre de 1989). La movilidad registrada se debe al mantenimiento de inversiones agrarias animadas por el deseo de recuperación de la rentabilidad económica de años anteriores. Por otra parte, una serie de procesos extraagrarios se sumaron a las complejas valoraciones que regulan el mercado de al tierra (construcción de la Autovía del Mediterráneo, instalación de un polígono del SEPES en la carretera Monforte-Pozoblanco ${ }^{9}$ y abandono de parcelas próximas al núcleo urbano ante expectativas de cambios de usos del suelo por el planeamiento municipal).

Se pueden hacer varios distingos que caracterizan esta tercera etapa respecto a las anteriores; ahora son poco frecuentes las inversiones en tierras para transformar en regadío, tanto por resultar escasas las dotaciones de agua para riego como por los elevados costes económicos que conlleva su puesta en producción. La oferta de tierras en plena capacidad de producción al ser abundante y a precios más asequibles que en los años anteriores, se suma a los factores que explican la escasa transformación en regadío de estos últimos años de la década de los ochenta. El mercado de la tierra únicamente se ve dinamizado para fines exclusivamente agrarios por los titulares de explotaciones familiares y por los asalariados en otras explotaciones agrarias. La falta de eficacia económica en las unidades de explotación agraria conlleva una caída del $25 \%$ en el precio por tahúlla (de 500.000 pts. a 300.000 pts. $)^{10}$.

Por último, se debe señalar que las políticas comunitarias, promulgadas estos años, no han favoreciendo dinamicas de compraventa. $\mathrm{Al}$ respecto hay que mencionar el reglamento comunitario que prima el arranque definitivo de viñedo, por la elevadas primas pagadas (1.100.000 pts./Ha), que ha hipotecado las posibilidades de venta de numerosas explotaciones agrarias, al impedir el cultivo de este arbusto durante 20 años.

\section{Análisis de los movimientos de tierra}

El mercado de la tierra del municipio de Monforte del Cid ha sido dinamizado por dos grupos socio-profesionales bien caracterizados (vid. fig. $\mathrm{n}^{\mathrm{o}} 2$ y 3 ):

- titulares de explotaciones agrarias cuya profesión principal no es la actividad agraria (obreros, industriales, comerciantes, profesiones liberales).

8 Los precios máximos pagados por metro cúbico llegaron a triplicar esta cantidad.

9 Este polígono ha movilizado 1,5 millones de $\mathrm{m}^{2}$.

10 Es de notar que en enclaves con fines residenciales en los parajes de Orito, La Capitana o Cubas, el precio por tahúlla alcanzaba 600.000 ptas. 
FiguRa 1. Evolución de la superficie transferida en Monforte del Cid (1980-1991)

Fuente: Comunidad de Regantes. Cámara Agraria Local.

EVOLUCIÓN DEL NÚMERO DE TRANSACCIONES POR COMPRA-VENTA Y HERENCIA EN MONFORTE DEL CID DURANTE EL PERÍODO 1980-1991

TRANSACCIONES

\begin{tabular}{|lcccccc|}
\hline & \multicolumn{2}{c}{ Por compra-venta } & \multicolumn{2}{c}{ Por herencia } & \multicolumn{2}{c|}{ Totales } \\
\hline & $\begin{array}{l}\text { Núm. de } \\
\text { transacc. }\end{array}$ & $\begin{array}{r}\text { Núm. de } \\
\text { tahúllas }\end{array}$ & $\begin{array}{l}\text { Núm. de } \\
\text { transacc. }\end{array}$ & $\begin{array}{l}\text { Núm. de } \\
\text { tahúllas }\end{array}$ & $\begin{array}{c}\text { Núm. de } \\
\text { transacc. }\end{array}$ & $\begin{array}{c}\text { Núm. de } \\
\text { tahúllas }\end{array}$ \\
\hline 1980 & 52 & 547 & 7 & 42 & 59 & 589 \\
1981 & 55 & 409 & 10 & 276 & 65 & 685 \\
1982 & 95 & 1.416 & 80 & 831 & 175 & 2.247 \\
1983 & 106 & 1.049 & 48 & 353 & 154 & 1.402 \\
1984 & 122 & 956 & 53 & 483 & 172 & 1.439 \\
1985 & 79 & 1.163 & 37 & 317 & 116 & 1.480 \\
1986 & 87 & 1.493 & 34 & 304 & 121 & 1.797 \\
1987 & 98 & 1.353 & 44 & 895 & 142 & 2.248 \\
1988 & 74 & 907 & 28 & 253 & 101 & 1.160 \\
1989 & 88 & 982 & 25 & 267 & 113 & 1.249 \\
1990 & 23 & 768 & 16 & 125 & 39 & 893 \\
1991 & 37 & 665 & 25 & 357 & 62 & 1.022 \\
\hline TOTALES & 916 & 11.708 & 407 & 4.503 & 1.323 & 16.211 \\
\hline
\end{tabular}

Fuente: Comunidad de Regantes de Monforte del Cid. Cámara Agraria Local. 


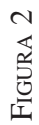

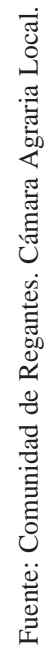


点 


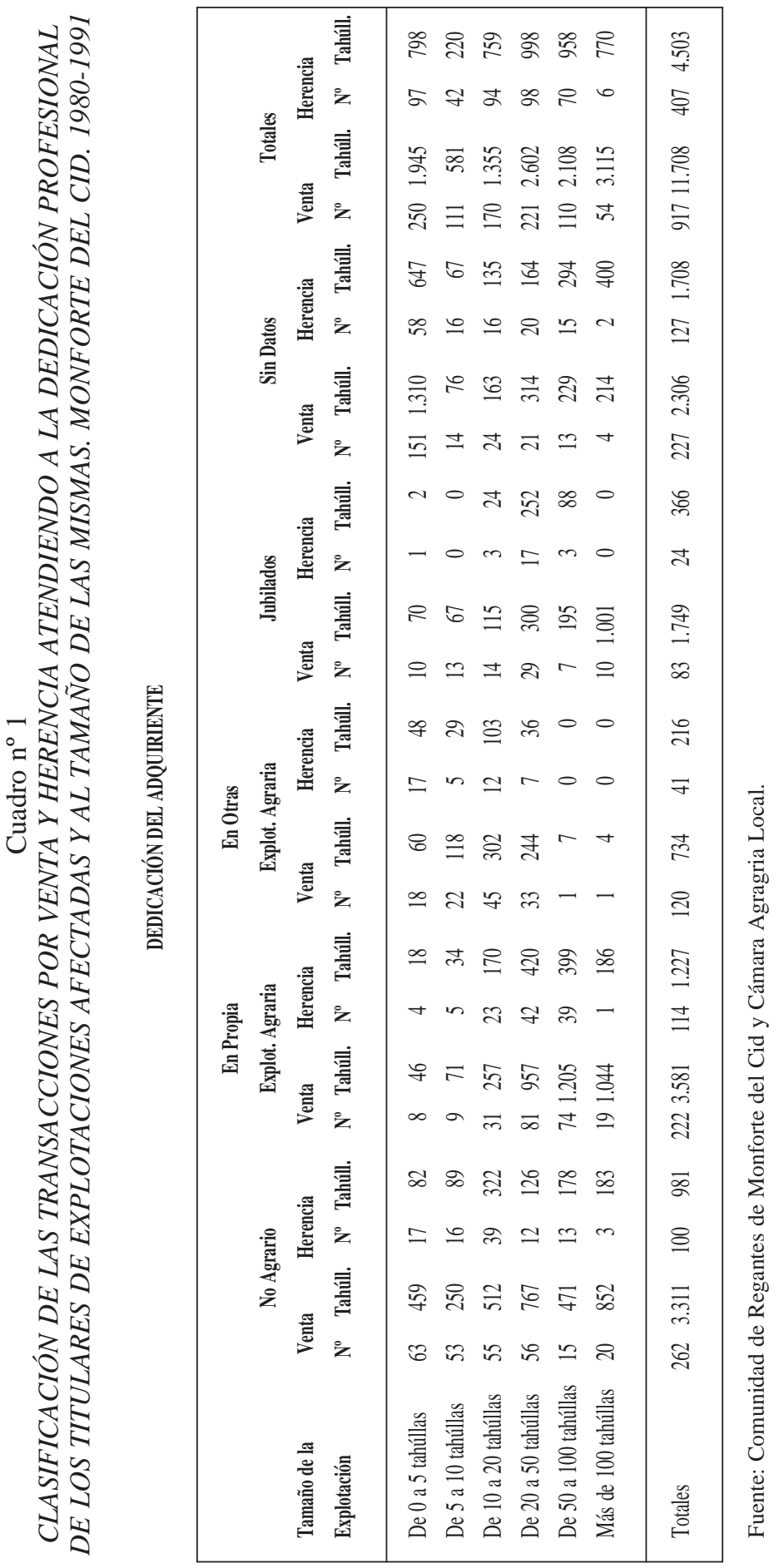




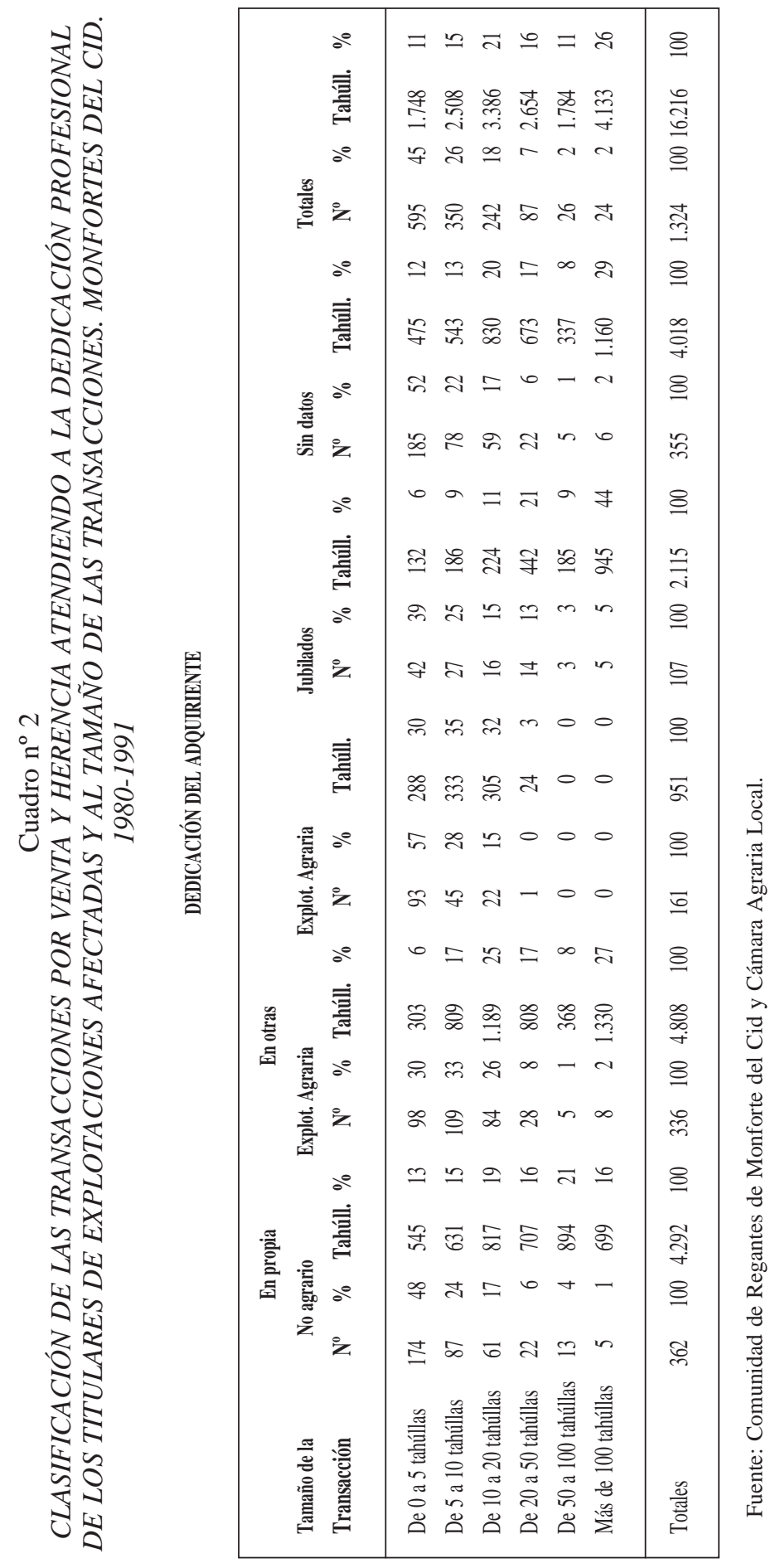


- titulares de explotaciones agrarias que ejercen la actividad agraria en su propia explotación como fuente de ingresos principal.

\section{Agricultores a tiempo parcial}

Este grupo socioprofesional acapara el $28,5 \%$ del total de las compras y el $24,5 \%$ de las herencias, mientras que sólo suponen un $9 \%$ de las ventas realizadas durante el período analizado (vid cuadros $\mathrm{n}^{\circ} 1 \mathrm{y} \mathrm{n}^{\circ} 2$ ). Los agricultores a tiempo parcial que participan en el intercambio de tierras se caracterizan por adquirir unidades de explotación pequeñas $(86 \%$ de las explotaciones involucradas son con frecuencia inferiores a 50 tahúllas ${ }^{11}$ ), y ello por el carácter parcial de su dedicación. Suelen ser titulares con edades comprendidas entre 25 y 55 años, y con capacidad de innovación (es habitual el empleo de riegos localizados).

Por su parte, las parcelas vendidas, dentro de este grupo profesional, no suelen exceder 10 tahúllas (76\% de las ventas). Se debe señalar una diferencia respecto a los adquirientes no agrarios, puesto que como cesionarios, este grupo socioprofesional siempre tiene edades superiores a 35 años.

En general, la mayoría de compradores y vendedores de este segmento profesional no son vecinos de Monforte; residen en las ciudades vecinas de Novelda, Elche, Elda, Alicante y Aspe (60\%). En esos casos se trata de emigrantes monfortinos instalados en las citadas ciudades y empleados en actividades no agrarias; algunos de ellos adquirieron tierras por las ventajas comparativas que ofrecía el mercado de Monforte respecto a las las condiciones imperantes en sus municipios de residencia (menor oferta y precios más elevados de la tierra).

El elevado precio por hectarea de regadío alcanzado en las tierras de Monforte del Cid, encuentra explicación, en gran medida, en la participación de este grupo socioprofesional en el mercado local de la tierra. Ello se explica por una serie de aspectos que señalan la influencia del mercado de la tierra y la importancia de la agricultura de regadío en la estructura económica de este municipio, a diferencia de lo ocurrido en otros del eje económico del Vinalopó eminentemente industriales (Elche o Elda). El despegue de la industria del mármol debido al auge del sector de la construcción de mediados de los ochenta, los efectos inducidos de la industria del calzado (Elda y Elche), y la capitalidad de Alicante, provocaron una redistribución de mano de obra que por sus orígenes nunca rompió lazos con la actividad agraria, ejercida ahora como fuente de ingresos complementarios.

\section{Agricultores profesionales}

Existen dos tipos de propietarios agrarios: los que tienen dedicación principal en explotaciones ajenas a la suya, y los propietarios que trabajan en exclusiva en su explotación. Los primeros, más jóvenes, son los que acaparan el mayor número de compras y, por contra, el menor de ventas ante la inseguridad del trabajo asalariado y el deseo de independizarse económicamente, mientras que los segundos son los que mayor superficie de tierras han movilizado dentro del municipio. Mientras que los jornaleros compran esencialmente parcelas catastrales menores de 5 tahúllas (vid cuadros $\mathrm{n}^{\circ} 1$ y $\mathrm{n}^{\circ} 2$ ), los agricultores empleados en su propia explotación adquieren parceles catastrales de mayor tamaño $(60 \%$

11 A finales de los ochenta las grandes explotaciones pertenecientes a este grupo socio-profesional, comenzaron a ofrecer resultados económicos insostenibles. Incapaces de cubrir los prestamos hipotecarios, fueron absorbidas por entidades bancarias que las abandonaron. 
de las transacciones con tamaño entre 5 y 20 tahúllas). Estos últimos además se caracterizan por ser residentes en el municipio (90\%), estar comprendidos en el grupo de edad de 45 a 55 años, y con un nivel adquisitivo superior a la de los titulares que trabajan en explotaciones ajenas. Este grupo socio-profesional es el que en mayor medida favorece la concentración parcelaria, al efectuar un gran número de compras de parcelas próximas a sus propiedades.

Por su parte, tres aspectos son los que motivan las ventas efectuadas por este último grupo socio-profesional:

- ventas realizadas para comprar, con posterioridad, parcelas próximas a otras en propiedad más rentables,

- ventas de una parte de los predios realizadas para costear las elevadas inversiones que exigían las transformaciones en regadío del resto de propiedades y,

- ventas realizadas por personas próximas a la jubilación y sin relevo generacional que optan por desprenderse de las tierras antes de abandonarlas.

Debemos señalar que los resultados económicos mínimos por hectarea que ha de ofrecer una explotación agraria en uva de mesa embolsada, para sostener una renta económica equiparable a la de otras actividades sitúa el umbral territorial mínimo en 30 tahúllas que pueden generar 3.500.000 pts. de ingresos brutos. Por debajo de esa dimensión difícilmente una explotación puede mantener a su titular a tiempo completo, y menos aún si emplea también a algún ayuda familiar ${ }^{12}$.

Por último, hay que indicar la falta de incentivos para el acceso a la propiedad de la tierra de los agricultores jóvenes. Aspecto que podría encontrar solución con la creación de un organismo dedicado a gestionar un banco de tierras procedentes de aquellas explotaciones agrarias cuyos titulares se acogiesen a planes de jubilación, tal como contempla la reforma de la Política Agraria Comunitaria.

\section{Jubilados, pensionistas y cesionarios sin identificar}

Jubilados y pensionistas participan activamente en las transacciones de tierra. Las transferencias - 266 cesiones y 3.334 tahúllas afectadas - que realiza este grupo duplican las adquisiciones. Son pues, unos de los principales grupos ofertantes de tierras, guardando este hecho relación con el cese obligatorio de la actividad agraria que impone la edad y el no mediar relevo generacional. Las parcelas cedidas suelen tener gran tamaño $(57 \%$ son mayores de 20 tahúllas). El 60\% de las cesiones realizadas por este grupo socioprofesional son por herencia, sobre todo cuando se trata de propietarios residentes en el propio municipio, mientras que en el apartado de ventas es usual que las realicen directamente antiguos agricultores a tiempo completo sin esperar a cederlas en herencia a unos hijos ocupados en otras actividades económicas.

Por su parte, los cesionarios sin identificar se caracterizan por su interés de permanecer al margen de las actividades agrarias ${ }^{13}$ o restringir su dependencia de dicha actividad. Son vendedores de tierra que han tenido un paso fugaz con la vinculación jurídica de la tierra y mucho más con la gestión de las explotaciones agrarias. Aunque muchos de ellos son propietarios absentistas, es también frecuente encontrar herederos que el mismo año o al siguiente transfieren el predio recibido, dada la elevada elevada cotización que la tierra alcanzaba en los años de mayor dinamismo. Las parcelas cedidas son de pequeño tamaño

12 Por explotación agraria familiar entendemos aquélla que tiene dimensión económica y territorial suficiente para mantener a tiempo completo al titular de la explotación y a algún ayuda familiar.

13 No aparecen en el Directorio de Explotaciones. 
(73\% inferiores a 10 tahúllas), a veces procedentes de ventas fraccionadas. Empero, el aspecto que más destaca es su importancia global en el mercado de tierra de Monforte del Cid al protagonizar el $45 \%$ de todas las transferencias (unas 841 cesiones) de tierra producidas en el municipio en el período analizado involucrando unas 10.181 tahúllas, es decir, un $63 \%$ de toda la superficie afectada por cambios de titularidad.

Merece la pena destacar que las más espectaculares transformaciones (en tamaño y capitalización) ocurridas en estos años en el municipio, es decir, las llevadas a cabo por propietarios no agrarios residentes en otros municipios, sobre todo de Novelda, fueron cedidas por compra por parte de jubilados o propietarios no identificados profesionalmente, residentes asimismo en municipios foráneos como Alicante o en capitales regionales como Valencia.

\section{Conclusiones}

Sin desdeñar la importancia que tiene el elevado número de transmisiones por herencia (4.503 tahúllas y 407 cesiones) parece razonable admitir que las consecuencias estructurales más importantes que derivan del mercado de la tierra durante el período analizado radican en las cesiones de propiedad por compra-venta (916 cesiones y 11.708 tahúllas). Se demuestra que los agentes más dinámicos en la adquisición de tierras han sido, por un lado, los agricultores profesionales con dedicación total a la explotación agraria y, por otro, inversores no agrarios que han ejercido la agricultura como una fuente de ingresos complementaria a la de otras actividades económicas. No obstante, la situación actual del mercado de la tierra es muy diferente a la descrita en la etapa de mayor dinamismo de compraventas (1982-1986). Con una oferta de tierras mayor a la de años precedentes, el volumen de transacciones ha descendido de modo notable; son pocos los compradores dispuestos a adquirir más tierras cuando las explotaciones agrarias son poco rentables. Ante esta situación el mercado de la tierra ha perdido movilidad pero sin disminuir de manera apreciable los precios de la tierra que siguen siendo elevados (4 millones/ptas/ha), hecho que se debe en gran medida a las expectativas que han introducido algunos compradores de tierras para fines no agrarios (segundas residencias, industrias del mármol, campo de golf). Los agricultores a tiempo parcial optan antes por abandonar la explotación acogiéndose a la prima por abandono definitivo de viñedo (1.250.000 ptas./ha) que por venderla a bajo precio; los agricultores profesionales son los únicos que adquieren alguna parcela cuando el precio y la ubicación son propicias.

Esta situación, común al resto de municipios del Medio Vinalopó, no favorece en modo alguno una evolución progresiva de las estructuras agrarias encaminadas, según los objetivos de la Política Agraria Común, a la configuración de un segmento de explotaciones agrarias dirigidas por agricultores profesionales. La creación de un banco de tierras comarcal, clasificadas por sus aptitudes de uso con precios fijados con criterios exclusivamente agrícolas; y el fomento del asociacionismo agrario (Comunidades de Bienes, Sociedades Agrarias de Transformación, Sociedades Anónimas) destinadas a la adquisición y transformación de las tierras ofertadas, son las soluciones más viables para remediar esta situación ${ }^{14}$.

14 Recientemente se han producido varias compras de tierras realizadas por parte de Sociedades Agrarias de Transformación en el municipio de Monforte del Cid y en Novelda. 


\section{Bibliografía consultada}

ARNALTE ALEGRE, E.: «La política de estructuras en la agricultura valenciana». En Estructura Económica de la Comunidad Valenciana. Edit. Espasa Calpe, 1992, pp. 419-439.

GIL OLCINA, A. y MORALES GIL, A. (eds.): Propiedad de la tierra en España. Departamento de Geografía, Facultad de Filosofía y Letras, Universidad de Alicante, Alicante, 1981, 489 pp.

OLCINA CANTOS, J.; RICO AMORÓS, A.M.; SUCH CLIMENT, M.P.: «Incidencia de episodios meteorológicos catastróficos en la actividad agraria del Valle del Vinalopó (Alicante)». En Papeles de Geografía, n 19, Universidad de Murcia, 1993.

ROMERO GONZÁLEZ, J.: La agricultura valenciana en el proceso de industrialización y urbanización. Serie Estudis, Generalitat Valenciana, Valencia, 1989. 258 p.

ROMERO GONZÁLEZ, J.: La agricultura valenciana en el proceso de industrialización y urbanización. Cambios estructurales en el período 1950-1990». En Medio siglo de cambios agrarios en España. Instituto de Cultura Juan Gil-Albert, Diputación Provincial de Alicante, Alicante, 1993, 884 p., pp. 363-392. 